\title{
ERRATA
}

\section{Masao SHINOHARA \\ Determination of peripheral color signal density using contrast-enhanced color Doppler ultrasonography in diffuse liver disease}

\section{J Med Ultrasonics (2004) 31: 53-58}

Errors appeared in the article cited above.

In the Subjects section, the third sentence should read as follows:

The etiologies of chronic liver diseases were chronic viral hepatitis in 31 patients (type B, 5; type C, 26), viral liver cirrhosis in 20 patients (type B, 4; type C, 16), alcoholic liver cirrhosis in 8 patients, and liver cirrhosis of miscellaneous causes in 3 patients.

Throughout the Results section, "Table 2" should read "Table 1." Also, on page 55, in the right column, on line 13, "Table 1" should read "Table 2."

M. Shinohara $(\varangle)$

Division of Gastroenterology and Hepatology, Department of

Medicine, Toho University, School of Medicine, 6-11-1 Omorinishi,

Ota-ku, Tokyo 143-8541, Japan

Tel. +81-3-3762-4151; Fax +81-3-3763-8542

e-mail: patho@med.toho-u.ac.jp 